\title{
Learner's Autonomy in Task-based Language Teaching for Instructional Design Practices: A literature review
}

\author{
Youngkyun Baek ${ }^{\mathbf{1}}$ and Sam Eisenberg ${ }^{\mathbf{2}}$ \\ ${ }^{1}$ Professor, Boise State University, Boise, ID 83725, USA \\ ${ }^{2}$ MET, Department of Educational Technology, Boise State University, Boise, ID 83725, USA
}

\begin{abstract}
Background/Objectives: This paper aims to discuss the ways in which instructional design practices can be improved through the use of task-based learning and strategy-based instructional approaches. Methods/Statistical analysis: Recent studies on task-based language (TBL) and strategy-based approaches to language teaching were reviewed to discuss their implications for instructional design. Findings: The researchers found that task-based learning approaches can cultivate learner autonomy; however, it is necessary to provide the appropriate amount of scaffolding in order to ensure that learners do not construct false knowledge. Furthermore, strategies should also be taught to learners in order to become more successful learners. Some strategies include instructional strategies, like modeling, as well as learner strategies that involve recognizing lexical patterns and metacognitive strategies. Improvements/Applications: Through the implementation of TBL and SBI, instructional designers can create curricula that encourage learners to become more autonomous and effective foreign language learners.
\end{abstract}

\section{Index Terms}

Instructional design, Language teaching, Learner's autonomy, Strategy-based instruction, Task-based Learning and Teaching, Instructional Design

\footnotetext{
Corresponding author : Y. Baek

youngkyunbaek@boisestate.edu

- Manuscript received November 2, 2021.

- Revised November 30, 2021; Accepted December 20, 2021.

- Date of publication December 31, 2021.

(c) The Academic Society of Convergence Science Inc.

2619-8150 @ 2019 IJASC. Personal use is permitted, but republication/redistribution requires IJASC permission.
} 


\section{INTRODUCTION}

The role of an instructional designer is to improve educational curricula and materials. When designing a curriculum, an instructional designer should take into account the various approaches to learning and teaching. One popular approach is the Task-based Language Teaching (TBLT) approach, which has been implemented in the classroom as a way to motivate learners and ensure that acquisition occurs. TBLT refers to the approach of teaching where a learner has to solve problems that simulate real-life scenarios [1]. This approach is characterized by qualities, such as "learner-centered," "comprehensive," and "learning by doing" [2,3]. One important prerequisite of TBLT is learner autonomy, which Niemiec and Ryan (2009) define as "the experience of behaviour as volitional and reflectively self-endorsed" (p.139) [4,5]; and Almusharraf (2018) describes it as “a learner's willingness to take...responsibility for participating, applying, monitoring, and evaluating his/her learning, which is usually developed with the support of a teacher" (p. 160) [6]. Learner autonomy might also foster a higher motivation to continue learning a foreign language, especially in regard to vocabulary [6]. For example, in a study on English as Second Language (ESL) learners in the Kingdom of Saudi Arabia, participants were observed and given a questionnaire, in which they indicated that they were motivated to learn English outside of class by watching movies in English as well as reading in the target language [6]. As learner autonomy is voluntary and independent, learners were able to find personal relevance to continue learning English on their own. Additionally, Muñoz-Restrepo, Ramirez \& Gaviria (2020) suggest that activities that promote learner autonomy may positively impact language achievement [7]. Furthermore, such tasks that can promote autonomy can also be completed in pairs or in small groups. For example, learners can work together online to propose a new movie or series that can be hosted on Netflix [8]. Ciubăncan (2013) suggests that tasks can cultivate new experiences for the learner, which can "correct, clarify, and deepen" their understanding (p. 61) [1]. Therefore, task-based learning should be implemented within the design of foreign language instruction.

Like TBLT and TBL, constructivist theory also emphasizes the importance of learner autonomy and is learner-centered. Constructivist theory refers to the idea that knowledge is created by the learner and that knowledge is a process based on their personal experiences [9]. Karagiorgi and Symeou (2005) state that "empowering [learners] to make choices about how and what they will learn results [in] a shift from having all learners learning the same things to allowing different learners to learn different things" (p. 19) [9]. Similarly, Muñoz-Luna (2014) also suggests that constructivism encourages active learning, which makes them capable of using language [10]. However, there are some limitations to relying on learner autonomy and constructivist models. For example, there is always the possibility that the learner constructs knowledge inaccurately [9,11]. Moreover, Neville \& Britt (2007) discourage providing too much scaffolding as the learner "runs into the risk of being led to a solution rather than developing their own" (p. 239) [12]. In order to ensure that the learner is autonomous, yet accurate, it is necessary for the instructor to provide a sufficient amount of scaffolding without discouraging autonomous learning. If it is the instructor's role to facilitate, then it is the instructional designer's responsibility to create effective learning materials and design tasks and learning activities that are appropriate to the learner. An effective curriculum should also be supported by effective language learning strategies, which should be taught to learners so that they can acquire the target language more successfully. This instructional approach is called Strategy-based Instruction (SBI), which can be defined as an approach to teaching that ensures learners are aware of the strategies, they are employing so that they can organize new knowledge [13]. Although it is important to reinforce learner autonomy, both the instructor and the instructional designer face the challenge of creating a curriculum that provides the precise amount of scaffolding in order to avoid having learners construct knowledge that is false. Despite this limitation, these approaches should not be neglected, and it is the aim of this paper to address this shortcoming, and to highlight the need of providing appropriate scaffolding, while still promoting learner autonomy.

\section{TASK-BASED APPROACHES TO LANGUAGE TEACHING}

TBL can boost motivation and achievement; for example, in a study conducted on Iranian ESL learners, the researchers found that learners who engaged in TBL outperformed those who did not in terms of their speaking ability [14]. This evidence suggests that TBL can improve instruction; and, therefore, it should be included in the curriculum design in order to provide more effective instruction for the learner. Muñoz-Restrepo, Ramirez, \& Gaviria (2020) also suggest that a learners' motivation improves when "... [they] perceive that a lesson has personal value or relevance, they tend to engage more, make more efforts, and achieve more" (p. 178) [7,1517]. In order to make learning materials more relevant to the learner, Cey (2001) argues that these materials should be authentic in order to reflect real-life 
scenarios where the target language will be used [18]. Moreover, Klee and Truman (2020) also support the need for learning materials to be age-appropriate so that they can accurately reflect the learner's needs [19]. Therefore, the learner should be given tasks that require them to examine authentic materials, so that they can understand the relevance of the tasks at hand. Furthermore, the materials should also be adapted to the needs and/or interests of the learner. In order to properly assess what these needs entail, instructional designers must work with educators to appropriately analyze what the learner demographic is. For example, if the learner is an Engineering student, then the lesson should focus on teaching vocabulary related to Engineering content in the target language. Additionally, "Because learning is studentcentered... [the task-based approach] leads to students to become independent thinkers, capable of assessing a problem and discovering on their own the resources that can be used in its solution" (p. 239) [12]. If the learner cannot find relevance in the activity, they are more likely to struggle with the assignment. Therefore, classroom assignments and activities should not only be reflective of the content but should also be personalized in order to address the classroom's needs.

Willis $(1996,1998)$ proposed a model for TBLT, which include three phases: a pre-task activity, the task, and a post-task activity [19-21]. The pre-task activity provides exposure to the language topic. The task phase consists of the undertaking of the task, which may include planning and reporting. Lastly, the

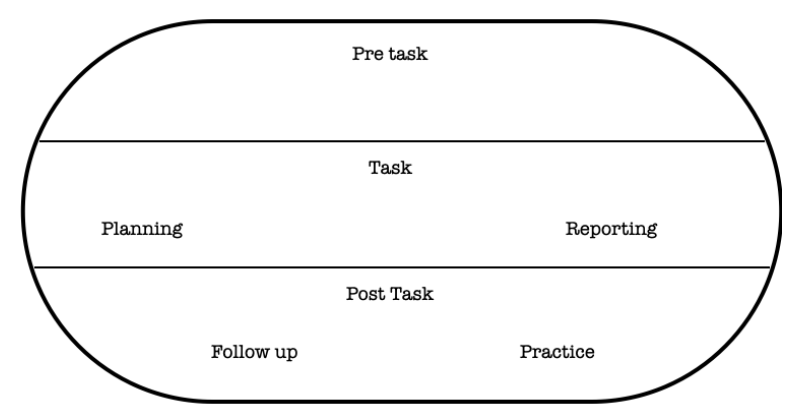

Fig. 1. TBLT learning cycle [19-21]

post-task activity allows for the learner to practice and review the knowledge. Figure 1 provides a model of the task-based learning cycle; a model which has been adapted from Willis original model [19-21]. Additionally, some learners may require more scaffolding and L2 tasks may need to be amended to fit the learners' level. In a study conducted on Japanese ESL students at the novice level, participants had to design, create and program a Lego object, draft an engineering and design report, and then reflect on it [3]. The researchers found that although the learners followed instructions, they could have performed better in regard to their technical writing and their design summary. Furthermore, they also had difficulties relating their projects to web-design principles. Despite the study's limitations, it is evident that TBL approaches had a positive effect on the students' motivation, as the researchers observed that they were engaged in classroom activities. When it comes to successfully implementing the problembased learning approach, it is imperative that both the instructional designers and instructors understand their learner demographic in order to create activities that appropriately connect course content to problems they may encounter in the real world. Nevertheless, novice learners might not have the language ability for completing a task autonomously and may require more scaffolding. As in the case of Roy's (2017) study, learners may have struggled to complete the activity due to the fact that they may not have had the English language ability to complete a task of that scale [3]. Furthermore, it seems that the course content may not have appropriately reflected content related to web design principles either. This highlights the need to ensure that assessment measures are not only reflective of the learner's ability but also their needs. Therefore, learner autonomy may need to be limited or increased based on the learner's language level.

\section{STRATEGY-BASED APPROACH TO LANGUAGE TEACHING}

Similar to a task-based learning approach, strategybased instruction is also learner-centered. "Strategybased instruction aims to assist learners in becoming more responsible for their efforts in learning and using the target language" (p. 66) [22]. Moya (2014) argues the need for students to take responsibility for their own learning and should learn language learning strategies, rather than rely on the instructor [22]. Being that learner autonomy is grounded in learners taking responsibility for their own learning, SBI can provide them with the tools necessary to work more independently and without the instructor's aid. Therefore, strategy-based instruction can reinforce the TBL approach, so that they are more appropriately equipped to complete the task. The strategies utilized by the learner should also be reflective of their age, personality, gender, and cultural background [23-26]. Although learners should understand which strategies to employ and when to employ them, scaffolding from the teacher may also be necessary in order to demonstrate how they should be used. Furthermore, Muñoz-Restrepo, Ramirez \& Gaviria (2014) state that "students can be more motivated when they are provided with the necessary guidance" (p. 179) [7]. One such way for the instructor to provide assistance 
while encouraging autonomy is modeling or demonstrating the desired action. This strategy can provide temporary and sufficient assistance until the learner is able to perform the desired action on their own. This may come in the form of talk-alouds and/or copies of the teaching materials, like an assessment rubric [20]. Therefore, modelling the strategy's use can demonstrate how it should be used and encourage learners to try it for themselves, so that they can build the confidence to then use it on their own.

Other types of learning strategies can focus on recognizing language patterns. Ranalli (2013) designed an online strategy instruction model with the goal of teaching learners how to recognize lexical patterns in the English language [27]. His instructional design model incorporates mainstream theories like Cognitive Load Theory and Multimedia Learning theory, and relies on "...online tasks to train and...multimedia presentations to convey the supportive and just in-time information" (p. 26) [27]. Through a combination of chunking text and images, learners will be presented with vocabulary and can then complete a plethora of text-based activities. It is not only the teachers' responsibility for teaching strategies, but web tools, that are used for ComputerAssisted Language Learning (CALL), can also provide instruction on strategies and reinforce this knowledge through constant evaluation. Furthermore, instructional designers may consider implementing online activities and/or technologies that can aid the learner with chunking new knowledge in the target language in order to recognize vocabulary and grammar structures. Teaching learners how to recognize grammatical patterns and vocabulary, and then organize this information is essential for reinforcing that this information is recalled later. Similarly, Lee and Heinz (2016) also found that repetition was key in regard to recalling new information [28]. Therefore, instructional designers will have to design activities that require repetition but are not monotonous in order to avoid boring the learners.

In terms of identifying language strategies, they can be divided into two categories: metacognitive and cognitive. Metacognitive strategies may include: "seeking to use [the target language] in as many ways as possible, having clear goals for [improvement], and thinking about progress" (p. 90) [29]. Cognitive strategies on the other hand can be exemplified as "trying to talk like native speakers, [taking] notes, [and writing] letters, and messages in [the target language" (p. 89) [29]. Lee and Heinz (2016) found that learners who were successful in learning a foreign language, often used metacognitive strategies [28]. These learners iterated that the strategies that helped them were memorizing expressions and incorporating them into their language repertoire; exposing themselves to authentic language materials; and reading aloud in the target language. Additionally, other activities that encourage the use of metacognitive strategies are mind mapping, which helps the learner to plan and systematize their knowledge [30]. This means that learners can prioritize which strategy is necessary for the activity at hand. Thus, if learners are able to identify the strategies they need to use, they can rely less on their teacher for scaffolding. Once learners begin to rely less on their instructor for guidance, they can become independent and ultimately, more autonomous. Therefore, this emphasizes the need for metacognitive strategies to be taught within the strategy-based curriculum.

Metacognitive strategies, like brainstorming, selfmonitoring, and making predictions, are also some strategies that are used in reading. In a study that examined metacognitive strategies used for ESL reading activities, the researchers found that participants had generally improved their reading comprehension when they employed these strategies [31]. The researchers also believe that learners may have utilized these metacognitive strategies because the participants had revealed that they were aware of the strategies they had utilized. One metacognitive strategy that correlates with successful language learning is planning and/or brainstorming [32]. Unfortunately, it is one of the less commonly used strategies; for example, in Sun's (2013) study that examined the learning strategies Chinese ESL learners employed, he found that learners were less likely to use metacognitive strategies, like planning [33]. Before starting a task, learners should first plan their course of action which can be supported by the instructor's guidance and/or by their classmates. Furthermore, the instructor should model how to effectively brainstorm in order to help the learner employ this strategy more successfully. Based on Sun's (2013) study, it seems that metacognitive strategies like planning may not be taught or are not taught effectively [33]. Thus, task-based activities should incorporate activities related to planning, so that they can become more effective learners.

\section{CONCLUSION}

The focus of designing a successful foreign language curriculum should utilize approaches that encourage learner autonomy. However, some learner groups may require some more scaffolding than others. Additionally, it is instructional designers' responsibility to ensure that the learning materials are relevant to the learner. In order to accurately assess the needs of the learner, Tessmer and Richey (1997) highlight the necessity of conducting a contextual analysis and the importance of designing instruction that is "situation-specific" (p. 88) [34]. An 
instructional designer must understand the implications, in which the learning will take place. This may include and is not excluded to analyzing the demographic (i.e., is the learner at the novice or advanced level); what is the role of the educator; and creating learning outcomes that are accurately aligned to the assessment. Once a proper contextual analysis is conducted, instructional designers and educators can identify ways in which the learner can practice using metacognitive strategies, like goal setting and self-reflection. That way, instructional designers and instructors can improve the learners' chance of success.

Not only should instructional designers and teachers work together to establish clear learning goals, it is also important for learners to be encouraged to set their own goals. This will motivate them to take responsibility for their own learning; and ultimately, become autonomous. Nonetheless, the ultimate goal of both the instructional designer and the educator is to design instruction that fosters the development of this autonomy, while ensuring that correct knowledge is reinforced. This should be achieved through the use of designing lessons that utilize a constructivist framework with both task-based and strategy-based instructional approaches. The true role of the instructional designer is to create materials that can aid the learner to acquire the knowledge needed, while the role of the teacher is to facilitate this knowledge acquisition. Through careful planning and collaboration, building task-based curricula that can not only help the learner acquire the second language, but also master the strategies that facilitate this acquisition to occur are essential. Moreover, teachers can become overburdened; therefore, it may be in the best interest of academic institutions to hire instructional designers in order to alleviate some of their burden. Instructional design can sometimes require the insight of subject-matter experts, which in this case, are the educators. Furthermore, by including instructional designers in the construction of learning materials and developing curricula, educational institutions may be more successfully adept at ensuring that students construct the necessary content knowledge and to eventually effectively acquire the target language.

\section{REFERENCES}

[1] Ciubăncan, M. (2013). From task-supported teaching to task-based learning: the case of Japanese language teaching in Romania. Euromentor Journal, 4(1), 56-65.

[2] Wilson, J. (1986). Task-based language learning. In D. Harper (Ed.), ESP for the University (pp. 26-43). Oxford: Macmillan Education.

[3] Roy, D. (2017). Task-based EFL language teaching with procedural information design in a technical writing context. Cogent Education, 4(1), 1-23. Campos, C. S. (2012). The use of metacognitive strategies in L2 reading. Lenguas Modernas, (40), 125-147.

[4] Niemiec, C. P., \& Ryan, R. M. (2009). Autonomy, competence, and relatedness in the classroom Applying selfdetermination theory to educational practice. Theory and research in Education, 7(2), 133-144.

[5] Diep, A. N., Zhu, C., Cocquyt, C., De Greef, M., Vo, M. H., \& Vanwing, T. (2019). Adult learners' needs in online and blended learning. Australian Journal of Adult Learning, 59(2), 223-253.

[6] Almusharraf, N. (2018). English as a foreign language learner autonomy in vocabulary development: Variation in student autonomy levels and teacher support. Journal of Research in Innovative Teaching and Learning, 11(2), 159-177.

[7] Muñoz-Restrepo, A., Ramirez, M., \& Gaviria, S. (2020). Strategies to enhance or maintain motivation in learning a foreign language. Profile, 22(1), 175-188.

[8] González-Lloret M. Collaborative tasks for online language teaching. Foreign Language Annals. 2020; 53: 260-269.

[9] Karagiorgi, Y., \& Symeou, L. (2005). Translating Constructivism into Instructional Design: Potential and Limitations. Educational Technology \& Society, 8 (1), 17-27.

[10] Muñoz-Luna, R. (2014). From drills to CLIL: the paradigmatic and methodological towards the integration of content and foreign language. Profile, 16(1), 167-180.

[11] Perkins, D. N. (1999). The many faces of constructivism. Educational Leadership, 57 (3), 6-11.

[12] Neville, D. O., \& Britt, D. W. (2007). A problem-based learning approach to integrating foreign language into engineering. Foreign Language Annals, 40(2), 226-246.

[13] Marzban, A. \& Isazadeh, F. (2012). Discovery listening and explicit strategy-based- instruction models' effect on the Iranian intermediate EFL listening comprehension. Procedial, Social and Behavioural Sciences, 46, 5435-5439.

[14] Khoshsima, H., \& Shokri, H. (2016). The effects of ESA elements on speaking ability of intermediate EFL learners: A task-based approach. Theory and Practice in Language Studies, 6(5), 1085-1095.

[15] Miller, R. B., \& Brickman, S. J. (2004). A model of futureoriented motivation and self-regulation. Educational Psychology Review, 16(1), 9-33.

[16] Vansteen-kiste, M., Simons, J., Lens, W., Soenens, B., \& Matos, L. (2005). Examining the motivational impact of intrinsic versus extrinsic goal framing and autonomysupportive versus internally controlling communication style on early adolescents' academic achievement. Child Development, 76(2), 483-501.

[17] Wigfield, A., \& Eccles, J. S. (2000). Expectancy-value theory of achievement motivation. Contemporary Educational Psychology, 25(1), 68-81.

[18] Cey, T. (2001). Moving towards constructivist classroom, retrieved December 19, 2004 from http://www.usask.ca/education/coursework/802papers/ceyt/c eyt.htm.

[19] Willis, J. (1996). A Framework for Task-Based Learning. Harlow, Essex: Addison Wesley Longman. Longman.

[20] Willis, J. (1998). Task-based learning? What kind of adventure? Retrieved April 22, 2005 from, http://langue.hyper.chubu.ac/jp/jalt/pub/ttl/98/jul/willis.html

[21] Hung, N. V. (2012). Mother tongue use in task-based language teaching model. English Language Teaching, 5(8), 23-30.Klee, C., \& Truman, L. (2020). New perspectives on the individual learner: implications for research and teaching. Second Language Research \& Practice, 1(1), 10-24.

[22] Moya, M. R. (2014). Reconsidering a strategy-based instruction (SBI) to teaching and learning another language using transferrable language learning strategies within a sociocultural framework. Matices En Lenguas Extranjeras, (8), 49-82.

[23] Chamot, A. U. (2009). The calla handbook: Implementing the cognitive academic language learning approach (2nd ed.). White Plains, us: Pearson-Longman. 
[24] Cohen, A. D. (2014). Strategies in learning and using a second language (2nd ed.). London, uk: Routledge.

[25] Oxford, R. L. (2013). Teaching and researching: Language learning strategies. London, uk: Routledge.

[26] Guapacha-Chamorro, M. E., \& Benavidez-Paz, L. H. (2017). Improving language learning strategies and performance of pre-service language teachers through a CALLA-TBLT model. Profile, 19(2), 101-120.

[27] Ranalli, J. (2013). Designing online strategy instruction for teaching knowledge of english word patterns as a complex cognitive skill. CALICO Journal, 30(1), 16-43.

[28] Lee, J., \& Heinz, M. (2016). English language learning strategies reported by advanced language learners. Journal of International Education Research, 12(2), 67.

[29] Sadeghi, K., \& Khonbi, Z. A. (2015). Language learning aptitude (LLA) and language learning strategy (LLS) use among Iranian university EFL students: Patterns and relationships. Eurasian Journal of Applied Linguistics, 1(1), 77-96.

[30] Mekala, S., \& Radhakrishnan, G. (2019). Promoting selfregulated learning through metacognitive strategies. IUP Journal of Soft Skills, 13(2), 21-27.

[31] Karimi, S., \& Dastgoshadeh, A. (2018). The effect of strategy-based instruction on EAP students' reading performance and reading autonomy. Cogent Education, 5(1), 1-19.

[32] Campos, C. S. (2012). The use of metacognitive strategies in L2 reading. Lenguas Modernas, (40), 125-147.

[33] Sun, L. (2013). The effect of meta-cognitive learning strategies on english learning. Theory and Practice in Language Studies, 3(11), 2004-2009.

[34] Tessmer, M., \& Richey, R.C. (1997). The role of context in learning and instructional design. Educational Technology, Research and Development, 45(2), 85-115. 